\title{
Spontaneous rupture of the bladder during vomiting
}

\author{
Ruairidh Crawford, Thomas Richard William Oliver, Hamid Abboudi, Shahzad Shah
}

West Hertfordshire Hospitals NHS Trust, Watford, UK

\section{Correspondence to} Ruairidh Crawford, ruairidh. crawford@yahoo.co.uk

Accepted 5 June 2017
CrossMark

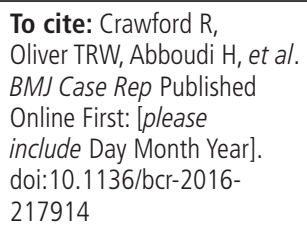

\section{SUMMARY}

A 46-year-old woman with no urological history or comorbidities presented with an acute abdomen with haematuria after a spell of protracted vomiting. The initial cystogram was negative; however, CT imaging highly suggested an intraperitoneal bladder perforation, which was confirmed during laparotomy and subsequently repaired. Cystoscopic evaluation prior to laparotomy revealed no concurrent bladder pathology, and the ureteric orifices were intact. A cystogram 2 weeks after repair demonstrated no leaks, and her catheters were removed. She recovered well, with expectant postoperative pain and lower urinary tract symptoms settling on 3-month review. Spontaneous bladder rupture is a rare entity, with very few reports in the literature.

\section{BACKGROUND}

This unusual case is important, as it has demonstrated that even normal, healthy bladders may rupture during episodes of high intra-abdominal pressure. Cystography is the gold standard diagnostic investigation; however, this case highlights that CT may also be required to confirm the diagnosis.

\section{CASE PRESENTATION}

We report a case of a 46-year-old female patient, who developed a spontaneous bladder rupture while vomiting. She had no significant medical history, with no previous bladder pathology or lower urinary tract symptoms. Prior to her presentation, she had consumed seafood at dinner and soon after felt unwell with suspected food poisoning. She vomited violently at the restaurant and returned home feeling unwell. A few hours later, she was unable to void, despite having a full bladder. A further episode of violent vomiting in the early hours resulted in a large show of blood onto the floor; she was unsure whether this was from her urethra or vagina. She developed worsening lower abdominal pain and subsequently presented to the emergency department. On examination, her lower abdomen was tender with guarding. Her observations were normal, although she was in moderate to severe pain, requiring morphine to relieve it. She was initially referred to the gynaecologists due to the history of possible vaginal bleed, who subsequently referred to the on-call general surgical team.

\section{INVESTIGATIONS}

Her blood tests showed a white cell count of $21 \times 10^{9} / \mathrm{L}$ and slightly raised creatinine of $95 \mu \mathrm{mol} / \mathrm{L}$. Her haemoglobin was within the normal range. A CT scan of her abdomen and pelvis was arranged to
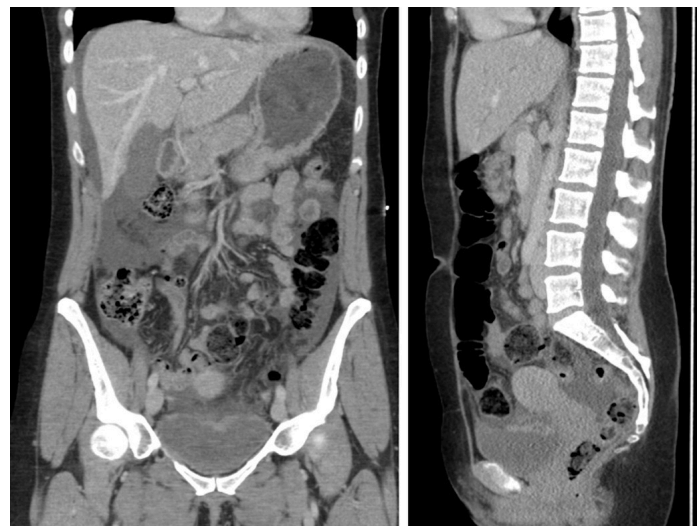

Figure 1 Coronal and sagittal CT images demonstrating irregular dome of bladder, with intraperitoneal fluid.

ascertain the diagnosis. This demonstrated a large volume of fluid within her peritoneum and an irregular dome of her bladder (figure 1). Her kidneys and other internal organs were unremarkable. A cystogram was then performed, which showed a smooth bladder outline, with no evidence of leak (figure 2). Due to the inconclusive cystogram findings, a CT cystogram was performed demonstrating contrast within the peritoneum and confirmed the diagnosis (figure 3 ).

\section{DIFFERENTIAL DIAGNOSIS}

The differential diagnosis for this presentation includes any cause for an acute abdomen, such as a hollow viscus rupture. Gynaecological causes such as acute ovarian torsion may have also presented similarly.

\section{TREATMENT}

After her initial CT scan that demonstrated intraperitoneal fluid, a $12 \mathrm{~F}$ urinary catheter was inserted. This drained only a small volume of mildly haematuric urine. Her urine output post catheterisation was poor. Intravenous antibiotics were administered. After the CT cystogram, the poorly functioning $12 \mathrm{~F}$ urinary catheter was replaced with a larger $16 \mathrm{~F}$ catheter. This drained over a litre of blood stained fluid over the next 1 to 2 hours.

Under general anaesthetic, a cystoscopy was performed to assess the extent of the perforation and to check the integrity of the ureteric orifices (figure 4). The perforation was visualised (figure 4), and the ureteric orifices were unaffected. A large clot adhered to the perforation was evacuated, and a soft ureteric catheter passed through the perforation into the peritoneum, to help identify the location of the perforation during laparotomy in 


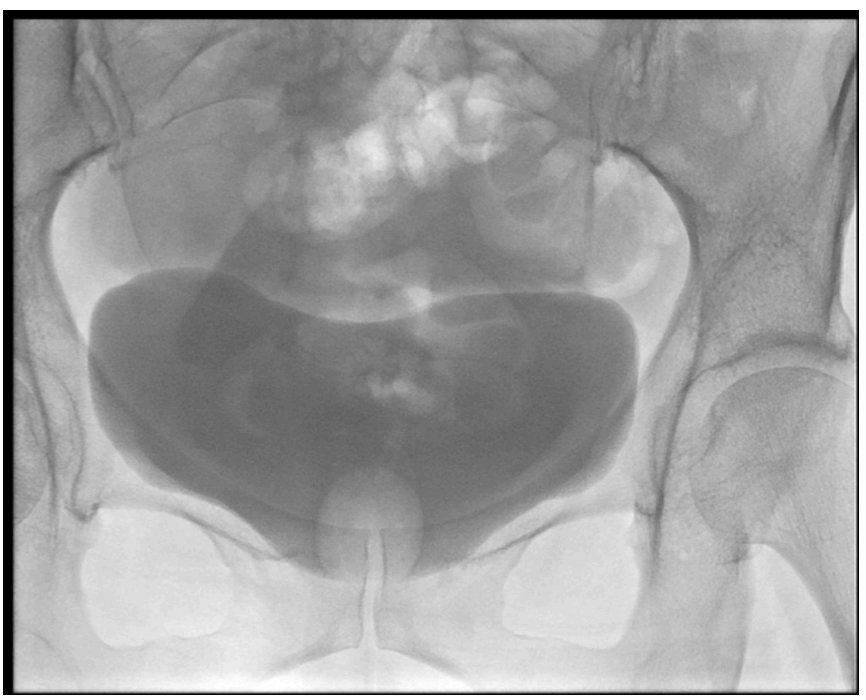

Figure 2 Cystogram demonstrating no obvious leak.

case of pelvic adhesions. The rest of the bladder mucosa was entirely normal, with no evidence of transitional cell carcinoma, inflammation, diverticuli or trabeculations. A bladder biopsy was taken from the edge of the perforation; the histology was benign. A lower midline incision was performed, and the peritoneum was opened. A $3 \mathrm{~cm}$ full thickness perforation was identified (figure 5), and a two-layer closure was performed using 2.0 Vicryl suture. A $16 \mathrm{~F}$ suprapubic catheter and a $16 \mathrm{~F}$ urethral catheter were inserted. The suprapubic catheter was inserted as well in case the urethral catheter became occluded from any further bleeding or clot formation. A 22F intraperitoneal Robinsons drain was also left in situ.

\section{OUTCOME AND FOLLOW-UP}

Postoperatively, she recovered well on the ward, and her intraperitoneal drain was removed on day 2 . She was discharged with both the suprapubic and urethral catheter on free drainage. A cystogram arranged 2 weeks later showed no leak. Both urinary catheters were removed. She did experience some postoperative pain and mild lower urinary tract symptoms during her recovery, although on review 3 months later, these had settled.

\section{DISCUSSION}

Spontaneous bladder rupture, in the absence of blunt or penetrating trauma, ${ }^{1}$ is a rare urological emergency. The perforation
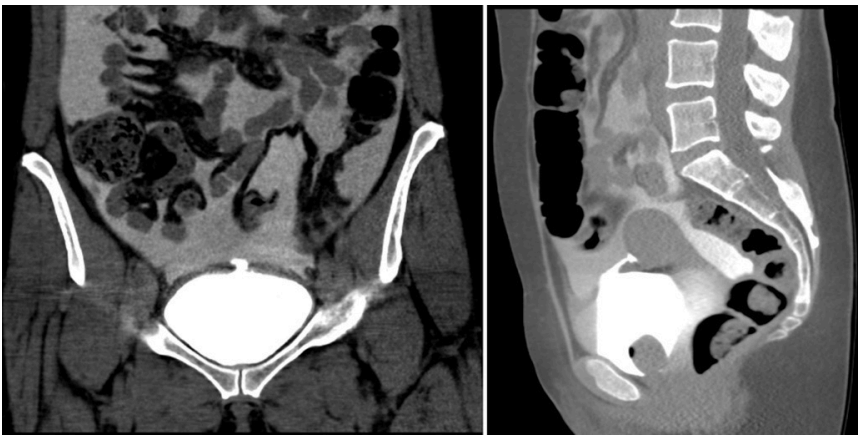

Figure 3 Coronal and sagittal CT images demonstrating intraperitoneal bladder perforation. The contrast from the first CT can be seen within the peritoneal fluid, and the contrast from the cystogram demonstrating the perforation.

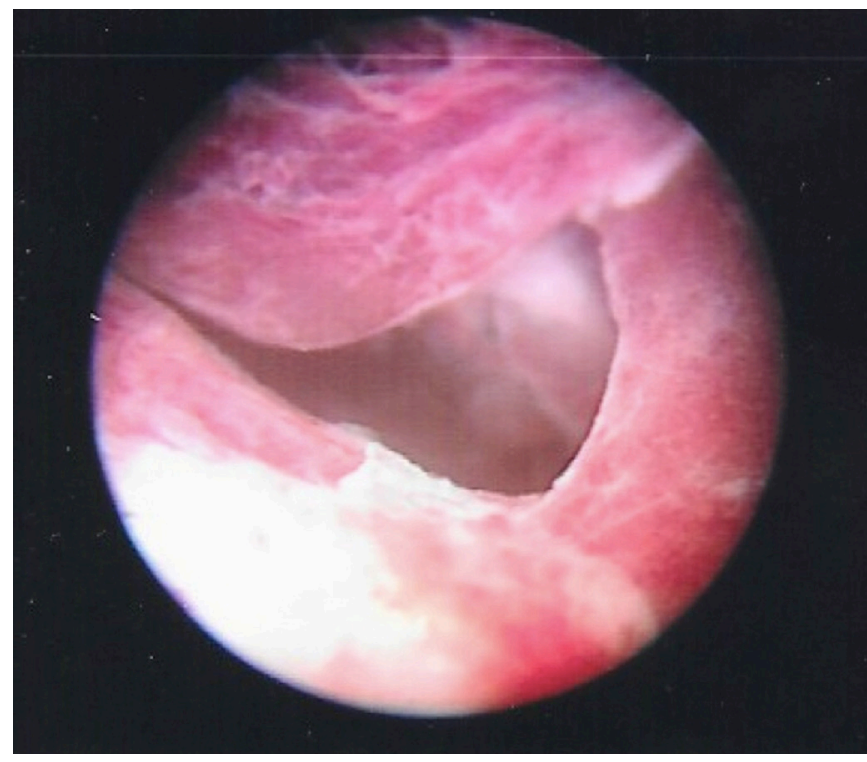

Figure 4 Cystoscopic view of the perforation.

tends to be intraperitoneal, typically presenting with a peritonitic, distended abdomen as well as haematuria, oliguria or anuria and deranged renal function. ${ }^{2} 3$ Its low incidence, in combination with a potentially non-specific presentation of an acute abdomen, means that many clinicians have a low index of suspicion for a bladder perforation with potentially grave consequences; undetected, the morbidity and mortality are high. The most common cause of urinary bladder perforation is damage to the urinary bladder wall during massive abdominal trauma or iatrogenic, endoscopic excision of bladder tumours or bladder stones, during gynaecological and general surgical interventions. Other less common risk factors include bladder malignancy, ${ }^{2}$ diverticulum, ${ }^{4}$ cystitis, ${ }^{356}$ pelvic irradiation, ${ }^{7}$ diabetes mellitus, ${ }^{8}$ neuropathic bladder, ${ }^{9}$ alcohol excess, ${ }^{10}$ postpartum $^{11}$ and chronic urinary outflow obstruction. ${ }^{12}$ Those cases that cannot be attributed to one of these are considered idiopathic, such as the patient reported here.

To our knowledge, spontaneous bladder perforation is a rare entity with few reports in the literature. ${ }^{13-17}$ One such case bears much resemblance to ours: sudden, rapid rise in intravesical

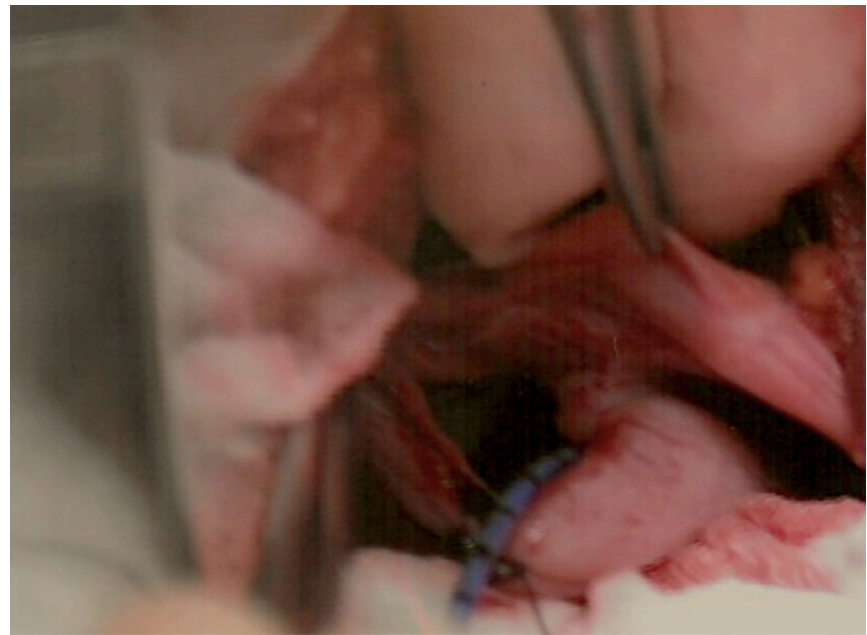

Figure 5 Intraoperative photograph showing the perforation with ureteric catheter passing through. Patient's perspective. 
pressure within an already distended bladder before developing haematuria and retention. ${ }^{17}$ This should act as a reminder of the importance of establishing a timeline of symptoms in these patients.

Spontaneous bladder perforation is often diagnosed intraoperatively, but should imaging be sought prior to surgery, cystography is the imaging modality of choice. In the case of our patient, the diagnosis was, unusually, made preoperatively despite a negative cystogram. With a previously reported diagnostic accuracy of $96 \%,{ }^{18}$ it emphasises the importance of trusting good clinical judgement over a negative gold standard investigation in suspected cases of urinary bladder perforation. The subsequent CT cystogram confirmed the rupture of the bladder dome. The reason for our negative cystogram may have been due to the large clot overlying the perforation, sealing the defect and preventing extravasation of contrast.

Previous case reports of intoxicated patients have hypothesised that the distended bladder is weakest at the dome, making it the most likely site for perforation in this case with a full bladder. ${ }^{10}$ The site of the perforation is important as it influences clinical management. For intraperitoneal injuries, the standard of care is surgical exploration with repair. However, if the perforation is small and the patient has multiple comorbidities and is not fit for general anaesthetic, a conservative approach with antibiotics and abdominal drain and a catheter may be considered. ${ }^{19}$ If the rupture is extraperitoneal, management is usually conservative with antibiotics and a urinary catheter maintaining a low-pressure bladder on free drainage.

Laparoscopic repair of intraperitoneal bladder rupture is reported in the literature as a safe and minimally invasive option in appropriate cases with an experienced laparoscopist. ${ }^{20-22}$ Patients should be clinically stable with only an isolated bladder injury present. We elected for open repair in our case due to the unusual presentation and the possibility of other injuries present.

In conclusion, if the diagnosis of a patient with an acute abdomen includes predominating symptoms of sudden abdominal pain, haematuria and coexisting acute kidney injury, one should consider the possibility of a urinary bladder wall rupture.

Contributors All authors were involved in the care of the patient during her admission at Watford General Hospital. The article was written by RLHC, and the

Learning points

- Always consider spontaneous bladder perforation in an acute abdomen following vomiting.

- Cystography may not always confirm a bladder perforation, and CT may also be required.

- Initial treatment of bladder perforation must include continuous bladder drainage through a large sized urinary catheter. literature review by TRWO and HA. The finished article was edited by SS, who was the consultant in charge of the patient's care.

Competing interests None declared.

Patient consent Obtained.

Provenance and peer review Not commissioned; externally peer reviewed.

(c) BMJ Publishing Group Ltd (unless otherwise stated in the text of the article) 2017. All rights reserved. No commercial use is permitted unless otherwise expressly granted.

\section{REFERENCES}

1 Sisk IR, Wear JB. Spontaneous rupture of the urinary bladder. J Urol 1929;21:517-21.

2 Ahmed J, Mallick IH, Ahmad SM. Rupture of urinary bladder: a case report and review of literature. Cases J 2009;2:7004.

3 Sawalmeh $\mathrm{H}, \mathrm{Al}$-Ozaibi L, Hussein A, et al. Spontaneous rupture of the urinary bladder (SRUB); a case report and review of literature. Int J Surg Case Rep 2015;16:116-8.

4 Nishimura T, Suzuki K, lijima M, et al. Spontaneous rupture of bladder diverticulum after postoperative radiotherapy for carcinoma of the uterine cervix: a case report. Radiat Med 2000;18:261-5.

5 Falk HC, Hochman S. Rupture of pelvic inflammatory masses into the urinary bladder. Am J Obstet Gynecol 1939;38:654-61.

6 Mardani M, Shahzadi M, Rakhshani N, et al. Spontaneous perforation of urinary bladder secondary to candida cystitis: acute abdomen of urologic origin. Surg Infect 2008:9:525-7.

7 Fujikawa K, Yamamichi F, Nonomura M, et al. Spontaneous rupture of the urinary bladder is not a rare complication of radiotherapy for cervical cancer: report of six cases. Gynecol Oncol 1999;73:439-42.

8 Kabarriti AE, Ramchandani P, Guzzo TJ. Spontaneous urinary bladder perforation: an unusual presentation of diabetes mellitus. Urol Case Rep 2014;2:109-11.

9 Aber A, Hyder SA, Arumuham V. An unusual case of spontaneous bladder perforation with associated autodialysis of the ensuing urinary ascites. Case Rep Med 2011;2011:1-3.

10 Muneer M, Abdelrahman $\mathrm{H}$, El-Menyar A, et al. Spontaneous atraumatic urinary bladder rupture secondary to alcohol intoxication: a case report and review of literature. Am J Case Rep 2015;16:778-81.

11 Sabat DK, Panigrahi PK, Sahoo RK, et al. Spontaneous puerperal extraperitoneal bladder wall rupture in young woman with diagnostic dilemma. J Family Med Prim Care 2015;4:601-3.

12 Jones AL, Armitage JN, Kastner C. Conservatively managed spontaneous intraperitoneal bladder perforation in a patient with chronic bladder outflow obstruction. Urol Ann 2014;6:370-2.

13 Uysal E, Dokur M, Ikidag MA, et al. Idiopathic spontaneous bladder perforation: a rare case. Urol J 2015;12:2119-21.

14 Al-Qassim Z, Mohammed A, England R, et al. Idiopathic spontaneous rupture of the urinary bladder (SRUB). A case report and review of literature. Cent European J Urol 2012;65:235-7.

15 Cusano A, Abarzua-Cabezas F, Meraney A. Spontaneous bladder perforation unrelated to trauma or surgery. Case Rep Child Meml Hosp Chic;2014:bcr2014204161.

16 Wieloch M, Bazylińska K, Ziemniak P. Spontaneous, idiopathic urinary bladder perforation-case report. Pol Przeg/ Chir 2013:85:727-9.

17 Simmons HT. Spontaneous rupture of the bladder. Proc R Soc Med 1929;22:1381-2.

$18 \mathrm{Hsieh} \mathrm{CH}$, Chen RJ, Fang JF, et al. Diagnosis and management of bladder injury by trauma surgeons. Am J Surg 2002;184:143-7.

19 Craggs B, Michielsen D. Conservative treatment of an intraperitoneal bladder perforation. Cent European J Urol 2011:64:47-9.

20 Marchand TD, Cuadra RH, Ricchiuti DJ. Laparoscopic repair of a traumatic bladder rupture. JSLS 2012:16:155-8.

21 Kim FJ, Chammas MF, Gewehr EV, et al. Laparoscopic management of intraperitoneal bladder rupture secondary to blunt abdominal trauma using intracorporeal single layer suturing technique. J Trauma 2008;65:234-6.

22 Matsui $\mathrm{Y}$, Ohara $\mathrm{H}$, Ichioka $\mathrm{K}$, et al. Traumatic bladder rupture managed successfully by laparoscopic surgery. Int J Urol 2003;10:278-80. 
Copyright 2017 BMJ Publishing Group. All rights reserved. For permission to reuse any of this content visit http://group.bmj.com/group/rights-licensing/permissions.

BMJ Case Report Fellows may re-use this article for personal use and teaching without any further permission.

Become a Fellow of BMJ Case Reports today and you can:

- Submit as many cases as you like

- Enjoy fast sympathetic peer review and rapid publication of accepted articles

- Access all the published articles

- Re-use any of the published material for personal use and teaching without further permission

For information on Institutional Fellowships contact consortiasales@bmjgroup.com

Visit casereports.bmj.com for more articles like this and to become a Fellow 